\title{
Beyond Cultural Identity: A Reading of Sanjay Nigam's Transplanted Man
}

\author{
Lihua Zhao \\ College of Foreign Languages, China West Normal University, Nanchong, China
}

\begin{abstract}
Indian American (Asian Indian) writer Sanjay Nigam's Transplanted Man seems to focus on cultural/ethnic identification, but careful examination would find what the novel really suggests is that other identities like ego identity, vocational identity, gender identity etc. are more important when it involves a person's unique sense of being. Besides cultural identification, all the characters explore and struggle to find a self that differentiates themselves from others, a universal topic for all no matter what racial, cultural, religious or educational background they come from.
\end{abstract}

Index Terms-Sanjay Nigam, Transplanted Man, identity, vocational identity, gender identity, ego identity, diaspora

\section{INTRODUCTION}

Indian American (Asian Indian) writer Sanjay Nigam was selected by Utne Reader as one of ten writers who represents the changing face of fiction. The Washington Post devotes one whole page to comment on Nigam's second book, Transplanted Man, claiming it a "work of considerable intellectual and imaginative energy" and "a charming, frolicsome book that dares to tackle complex issues." Asian Week claims that Transplanted Man has moved South Asian literature into the 21 st Century.

Setting at Little India, an ethnic enclave of Indian diaspora, Transplanted Man presents three seriously troubled characters: The Transplanted Man whose major organs are mainly transplanted from various sources, the Hypokinetic Man whose movement is incredibly difficult and slow and Sonny, a medical resident who sleepwalks and has nightmares. Interacting with these three one way or the other are other characters who suffer from insomnia, nightmares and uncontrolled appetite etc in varied degrees. To some extent, all of them are as hybridic as the transplanted man, as lost as the sleepwalker Sonny and as stuck as the hypokinetic man. Their problems root either in childhood trauma or in their physical deficiency or their career, but all of them share one same source. That is, their marginal existence between Indian and American culture or Eastern and Western culture. As Menaka notes: "Everyone seemed positioned on a number line that began here and ended in India. People were constantly adjusting their position on that line, never comfortable in their current spot. Go forward? Or backward? Maybe this was what caused Nirdosh to stay awake night after night and Tiger to scream in his sleep - not to mention her patients who sleepwalked or suffered from other parasomnias...... One way or another, they were all sleepwalkers." (Nigam, 2002, p.259) These hybridic sleepwalkers explore and struggle, fighting for a future and a direction and finally start to move towards the end of the story. The Hypokinetic Man who has not moved one step for months leaves the street corner where he has stationed; Sonali and her husband go to the American west after their failed home retuning trip to India; Manny and Alvin finally stop daydreaming and fly to India to try their dreams; Sonny quits his job and plans to go to Trinidad; Tiger reconfirms his spicy-spicy food but file for a green card. Dr. Giri becomes to be more and more committed to his double roles as Indian Guru and American psychologist.

Living in the in-between place, Little India, all of the characters are challenged by the choice of either to be an Indian or an American, either eastern or western. Cultural identification seems to be one thing that concerns them all. But the most important question is not the choice itself, nor what is Indianness and Americanness, but a more important question, that is: What I am or want as a unique human being on the basis of being an Indian diasporic. It is not the abstract, unifying Indianness that they are clinging to, or the abstract Americanness they are yearning for, but more importantly the individual uniqueness that comes from a combination of their cultural identity and other identities that differentiates them from any other human beings. They are constantly searching and exploring to find a perfect connecting point between their cultural identity and other identities. Cultural identity might play a very important role here in their defining of their individual uniqueness, but it has to give way when it conflicts with other identities that makes up their sense of being and that they are proud of, either in terms of gender or profession or others. This paper will examine what identity tangles the characters face and how they solve them.

\section{BEYOND CULTURAL IDENTITY}

On the surface, Tiger's story establishes him as an Indian who, for profits sake, tries to embrace American culture by changing his spicy-spicy Indian food to food with no hot pepper to cater for the tastes of American customers. And his 
returning to spicy-spicy food seems to suggest his inability to assimilate and his stubborn hold on his ancestral culture. But to conclude Tiger's story as a story of cultural identification through food would over-simplify the whole picture. Careful examination would find that he actually focuses more on his superiority in cooking as an artist and power as a king. For him, the spicy-spicy food does not only represent Indianness, but more importantly suggest art and power. In the only one description of Tiger's preparation of food, the novel emphasizes creativity and beauty of his cooking. "Despite his considerable bulk, Tiger moved gracefully......He metamorphosed into an artist, a conjurer in communion with another world. More than ever the divine logic of food flowed effortlessly from his fingertips into pots on the stove as he instinctively balanced hot with sour, cumin, turmeric, coriander, tamarind, cloves....." (Nigam, 2002, p.254) In Tiger's eyes, the Indian food he prepares is his "creation" and he is the best and the king in this field. Being the best artist and the king in this field establishes King's very ego identity and his sense of self and being, not just Indian. Therefore, abandoning spicy-spicy food does not just mean abandoning Indianness, but giving up his sense of being and killing his own strong ego. That is what Tiger fears the most and it explains why Tiger is so angered by Ronny's "patronizing tone", "condescending smile" and his accusation of Tiger's "cheap imitation" and "eunuch's existence".

Tiger's nightmares imply his fear of castration, a metaphor of loss of his ego and vitality. "We won't finish you off. We'll complete the process you've already begun. A swift stroke - two if they're as big as you claim. Of course, I've always been sure they were quite small, shriveled and droopy. Anyway, now we'll see. They'll just roll away. They're already so useless you won't miss them." (Nigam, 2002, p.257) For Tiger, abandoning spicy-spicy food connotes more than cultural assimilation but a loss of vitality and libido which is a great shame for the king Tiger as is shown clearly in his denial and hesitation when his doctor Menaka asks about his sex life. Therefore, his returning to Indian food can not be read as a resistance against assimilation, but a reclaim of his being and his vitality. For him, being Indian or American is not as important as his being the best artist in cooking Indian food. Therefore, sticking to spicy-spicy food and applying for a green card is not as contradictory as it seems. It simply shows that his identity as an artist and king shadows his national and cultural identity.

Similarly, Sonali and Nishad's story can only be partly read as a story of the conflict between Indian cultural identification and American cultural Identification. Nishad's problem with Sonali's big hips seems to suggest his Americanization or assimilation. Indeed he is accused by Sonali of "applying Western criteria to her body". (Nigam, 2002, p.46) She claims that he "has been turned into a perverse maniac by Hollywood and Madison Avenue!"(Nigam, 2002, p.96) But the real reason that Nishad bites Sonali's buttock is a strong urge of sexual desire caused by his appreciation of Sonali's voluptuous body instead of his former transient problem with his wife's big hips. The fact that Sonali's big hips remind him of the erotic sculptures Khajuraho, a very important and classic expression of Indian sexual ideas, and arouses his strong sexual desire suggests Nishad's Indianness is so deep that it is right there in his instincts. It is that relaxed moment that shows American standard of women beauty just blinds Nishad's eyes for a while and on the superficial level. That is to say, Nishad's try of American beauty value in a sense makes clearer his deep-rooted sexual instincts as an Indian man. But this does not indicate Nishad's total Indian cultural identification. Actually his changes at the latter part of the novel indicates that he discards Indian male chauvinism and becomes to be more understanding and tender, a husband who does not only help prepare meals but also let his wife do what she wishes in sex. Therefore, what matters is not to be Indian or American, but to be a better and happier person and husband.

Ironically, Sonali's defiance of her husband's Americanization and her hold on her Indian cultural identity seems to trigger her own assimilation. Sonalis's effort of fighting to keep their Indianness by accusing her husband of being "a pawn of neoimperialist”(Nigam, 2002, p.97), wearing only saris, speaking Indian only, seeing Indian movies, visiting the local temple for the first time and even going back to Indian, turn out to make her realize she has changed. She has changed both as an Indian and a woman. She "vowed never to see another Hindi film, concluding that they perpetuated the very entitled Indian male syndrome that was behind this whole mess." (Nigam, 2002, p.98) The feminist social worker and The Second Sex change her to be a new woman: "it may look as my husband bit my buttock, but in reality he bit my brain! Instead of debilitating me, though, it has energized me-given me a new perspective on life."(Nigam, 2002, p.96) This new woman sees clearly the Indian male chauvinism and rejects this part of Indianness. She dumps her traditional Indian woman role and takes the active and controlling role in her relationship with her husband, including in sex. But to attribute Sonali's feminist image as total Americanization or assimilation would also be over-simplification. Sonali's new woman image is not actually new in the whole sense. The novel makes sure that careful readers understand that Sonali has always been a strong female professional and has always been proud of her engineering career, engineering skill and her engineer's mind if readers pay attention to her repeated mention of all these in her consciousness. The strong woman has always been there hidden behind the sari of traditional Indian woman. That is why she follows Nishad's ideas in many things but has refused to have babies for years. Between the choice of being an Indian woman and a strong female professional, Sonali's choice has always been the latter, even when she is deliberately wearing saris, speaking Indian and seeing Indian movies. What matters the most for her is not to be Indian or American but to be a strong woman and a strong professional. Cultural identification has to give way if it conflicts with her gender and professional identification.

Moving back to the States and out of their Indian diasporic enclave, Little India, can not simply be read as Sonali's final renouncement of her Indian identity and claim of American identity as well. Moving west is not just for survival, 
but for her self-realization as a professional and her development as a new woman, a new independent, free and strong woman cutting from any Indian traditional gender role that binds her. "The Bay Area promised a new future - professionally as well as personally."(Nigam, 2002, p.330) For Sonali, it is not being an Indian woman or wife or American but being a "Ms. Woman of the Computer Age" that is important. Her professional identity is more important for her than her ethnic/cultural identity. It is for realization of her profession or self-realization that she goes to the States and it is also for her development in the engineering field that she goes back to India and then back to the States. She talks about the new India of computers, satellites and test-tube babies, cyberspace, and plans to go back to Indian to join firstly an engineering firm and then start their own. She is "so excited by the country's entrepreneurial spirit that she seemed to forget the strange circumstances that had brought them there. She couldn't get enough of the Delhi where she' $d$ been born and raised. All over the city Marutis and other small care filled the streets, mobile phone, this and that dot com, fashionable shopping centers, latest ultrasound equipment, computer rooms, internet access," (Nigam, 2002, p.309) To sum up, it is the identity of a strong female professional that makes up a uniqueness that Sonali cherishes and when cultural identity contradicts with it, Sonali makes her uniqueness more important.

For Sonny, cultural identity is even less important. Living outside Little India but working in Little India does not suggest his hesitation or dilemma between Indian identification and American identification. Like his been drawing to New York when at Arizona and feeling the pull of Arizona when in New York, it just indicates his inability to settle down. "he has to settle - inside. But he thinks finding where he need to be inside depends on finding where he needs to be outside. He has developed a whole theory about it, a theory of a perfect place." (Nigam, 2002, p.248) His nightmares and his sleepwalking problems show that his restlessness is not caused by a cultural dilemma but an unhappy childhood. Bad relationship with his mother and lack of father make him feel like an orphan. His dreams about searching for guidance from an old man and his tender feeling to the fatherly figure Transplanted Man suggest that, in his consciousness, being a protected and guided son is the most important thing for him. "This was the fourth or fifth night in a week that he'd dreamed about the old man in the desert telling him to go somewhere. But where?" (Nigam, 2002, p.28) He is just like a lost boy endlessly looking for a father but failed. "Deep within those eyes lurked a wild longing......It was the look of a young man searching for something beyond what the rest of the world was satisfied with, yet at the same time unsure what that was." (Nigam, 2002, p.37) In another dream, his yearning for a father is even clearer when he actually asks a group of men for a father.

Besides, Sonny's sleepwalking is also not caused by cultural conflict but by "an internal conflict so painful that it could be resolved only outside the bounds of consciousness." (Nigam, 2002, p.168) What is more, his resemblance and affinity for the Hypokinetic man suggests a state of being stuck and inability that is not caused by cultural dilemma as well since the hypokinetic man, a white in the States, does not have cultural identification problems. As a matter of fact, his belief and pursuit of a place for everyone shows that he does not want to identify with any culture, neither Indian nor American. Trinidad, "a place for everyone, where everybody has come from somewhere else, where the cultures are all mixed unencumbered by ancestral echoes." (Nigam, 2002, p.230) For Sonny, ancestral connections doe not provide a sense of home and belonging, but act as encumbrances.

Likewise, Dr. Giri's struggle with the guru's robes or the psychologists' white coat suggests more than cultural dilemma. For him, playing guru is just for survival, not for keeping his Inidanness. As a matter of fact, although refusing to leave Little India, he hates playing a guru because it shadows his identity as a psychologist, an identity that has nothing to do with American identity or that does not suggest assimilation either. Being a psychologist is just one very important element of his vocational identity other than cultural identity that makes him unique and gives him a sense of being. His vocational identity is far more important than his cultural/ethnic identity.

Manny's going to India can also not be read as his Indian cultural identification only. It is for his dream of being a playback singer, not for an Indian he is seeking. And the fact he goes with non-Indian Alvin strengthens that the trip is not for the sake of Indian identity, but for dreams and ambition, things that make them have a basic sense of self other than cultural identity.

What is more, the younger generation Atul and Jay's seeking for a pose for everyone and the sister's search for an ism for everyone to solve the fighting also make clear the weak significance of cultural identity for them. The writer's design of one Indian man growing up and living in India as the Transplanted Man and one white man living in the States as the Hypokinetic man further shows that even those non-diasporics might find themselves transplanted and stuck. The writer seems to emphasize that cultural/ethnic identity is just one among the many identity problems. Feeling lost, distant and unable to move and reach home is common and universal, diasporic or not. As is commented by some, Transplanted Man examines human questions that are without geographic boundaries.

\section{ANTHROPOLOGICAL EXPLANATION}

The weak cultural identifications of Indian Americans in the novel find its correspondence and explanation in anthropological studies as well. According to Maxine P. Fisher, Asian Indian immigrants who have come to the States after 1965 "lack a strong sense identity as Indians." (Fisher, 1978, p.271) Fisher (1978) attributes this phenomenon to two causes. One is the major shift in U.S. immigration policy which enabled Indians, esp. Indian professionals, to enter this country in significant numbers for the first time in half a century.

This system of issuing visas accounts for one of the most striking characteristics of the Indian immigrant 
population here: the degree to which it is professionally employed. For example, of the 14,939 Indians admitted as immigrants in 1975, 6,156 were classified by the U.S. Immigration Service as "professional/technical workers" (U.S.ISAR 1975:42-43). An additional 7,763 were classified as "spouses and children of professional/technical workers" (U.S.ISAR 1975:43). The combined figures account for 93\% of the Indian immigrants admitted during that year. Also, of the 188 Indians admitted in 1975 as "temporary workers" (a nonimmigrant status), 122 were classified as "workers of distinguished merit and ability" by the Immigration Service (U.S. ISAR 1975:70). ...... the government's statistics on the occupational status of Indian immigrants are impressive. In 1974 more than half of the 46,000 reported as employed were working as engineers, scientists, or in the medical profession (Doshi 1975:xii) (pp.272-274).

According to Fisher, most of these immigrants had good jobs at home and they came to the States for "greater job opportunity" (Fisher, 1978). The fact that career advancement is an important motivation for emigrating suggests that these mostly professional Indians value career more than anything else. A weak cultural identification is hence understandable. The novel does not state clearly the time of the story. But according to the information like the "computer age" the novel provides, we can assume it sets in the second half of the $20^{\text {th }}$ century, most probably the last two or three decades, during which most Indian immigrants came to the States were professionals. The novel's characterization of Sonali, Dr. Giri, Nishad and Dr. Ranjan etc. are all typical professionals who put their career before cultural identification and who would let go certain element of cultural identity if it contradicts with their career.

Another cause that Fisher finds for the weak Indian cultural identification is the diverse linguistic, religious, and regional backgrounds of the Indian immigrants:

The Indian immigrant population of New York is marked by a high degree of diversity in terms of its ethnic origin prior to emigration. Speakers of no fewer than 12 different Indian natal languages are represented here. There are, in addition, five broad religious categories, and sectarian divisions are recognized within these. Membership in different castes and varnas transect all of these identities. And finally, there are immigrants of Indian origin who have spent much or all of their lives outside of India, typically in an East African country. These people have an additional layer of ethnic identity superimposed on all of the above (Fisher, 1978, p.275).

Just as few Asians in America would identify as Asian Americans, the diversity of both the backgrounds and ethnic labels make it hard for the Indians in the States to identify as Indian Americans. As a matter of fact, the U.S. Census Bureau even did not provide a category for the Indians in America for their self-identification until 1980. The "ethnic background on the census questionnaire had only one box appropriate for Indian self-identification: a large residual category labeled "other." Census Bureau officials in Washington admitted that data on those responding "other" were added to data collected on those responding 'white/caucasian."'(Fisher, 1978, p.279)

\section{CONCLUSION}

To sum up, Sanjay Nigam's Transplanted Man presents a realistic picture of the identity exploration of the Indian Americans in New York City by depicting the complicated tangle of their multiple identities. Due to the strong ego identity, career identity or gender identity of these characters, cultural identity becomes less important when it contradict with other identities.

\section{ACKNOWLEDGMENT}

This paper was supported in part by a grant from National Planning Office of Philosophy and Social Science. It is the partial fulfillment of one project the author hosts: "A Study of the Spatial Memory and the Spatial Reconstruction of Thirty 20th Century American Minority Fictions" (National Planning Office of Philosophy and Social Science, 11CWW022).

\section{REFERENCES}

[1] Alcoff, Linda Martín. (2003). Latino/As, Asian Americans, and the Black-White Binary. The Journal of Ethics 7.1, Race, Racism, and Reparations, 5-27.

[2] Berbrier, Mitch. (2004). Assimilationism and Pluralism as Cultural Tools. Sociological Forum 19. 1, $29-61$.

[3] Bow, Leslie. (1999). The Gendered Subject of Human Rights: Asian American Literature as Postcolonial. Cultural Critique 41, 37-78.

[4] Brettell, Caroline B. (2005). The Spatial, Social and Political Incorporation Of Asian Indian Immigrants In Dallas, Texas. Urban Anthropology and Studies of Cultural Systems and World Economic Development34. 2/3, 247-280.

[5] Callan, Eamonn. (2005). The Ethics of Assimilation. Ethics 115.3, 471-500.

[6] Cheeseman, Nic. (2006). Introduction: Political Linkage and Political Space in the Era of Decolonization. Africa Today 53.2, 3-24.

[7] Douglas S. Massey \& Zoltan L. Hajnal. (1995).The Changing Geographic Structure of Black-White Segregation in the United States. Social Science Quarterly 76.3, 527-542.

[8] Edwards, Harry T. (2004). The Journey from Brown V. Board of Education to Grutter V. Bollinfer: from Racial Assimilation to Diversity. Michigan Law Review 102.5, 944-978.

[9] Fisher, Maxine P. (1978). Creating Ethnic Identity: Asian Indians in the New York City Area. Urban Anthropology. 7.3, 271-285. 
[10] Fisher, Maxine P. (1978). Creating Ethnic Identity: Asian Indians in the New York City Area. Urban Anthropology 7. $3,271-285$.

[11] Formes, Malia. (2005). Post-Colonial Domesticity Amid Diaspora: Home and Family in the Lives of two English Sisters from India, Journal of Social History 39.2, 467-482.

[12] Gonzales Jr., Juan L. (1986). Asian Indian Immigration Patterns: The Origins of the Sikh Community in California. International Migration Review 20. 1, 40-54.

[13] Jain, Anju \& Jay Belsky. (1997). Fathering and Acculturation: Immigrant Indian Families with Young Children. Journal of Marriage and Family 59. 4, 873-883.

[14] Julian, Teresa W. \& Patrick C. McKenry. (1994). Cultural Variations in Parenting: Perceptions of Caucasian, African-American, Hispanic, and Asian-American Parents. Family Relations 43. 1, 30-37.

[15] Kim, Claire Jean \& Taeku Lee. (2001). Interracial Politics: Asian Americans and Other Communities of Color. Political Science and Politics 34.3, 631-637.

[16] Lim, Shirley Geok-lin. (1993). Feminist and Ethnic Literary Theories in Asian American Literature. Feminist Studies 19. 3 , 570-595.

[17] Lowe, Lisa. (1998). The International within the National: American Studies and Asian American Critique. Cultural Critique 40, 29-47.

[18] Memmi, Albert. (2007). Decolonization and Decolonized. Canadian Journal of Sociology. http://www.cjsonline.ca/reviews/decolonized.html (accessed 29/4/2007).

[19] Nigam, Sanjay. (2002). Transplanted Man. New York: Harper Collins Publishers.

[20] Ono, Kent A. (2004). A Companion to Asian American Studies. Malden, USA: Wiley-Blackwell.

[21] Palumbo-Liu, David. (1994). The Minority Self as Other: Problematics of Representation in Asian-American Literature. Cultural Critique 28, 75-102.

[22] Priestley, George. (2007). Ethnicity, Class, and Race in the United States: Prospects for African-American/Latino. Latin American Perspectives 34. 1, 53-63.

[23] Pyke, Karen D. \& Denise L. Johnson. (2003). Asian American Women and Racialized Femininities: "Doing" Gender across Cultural Worlds. Gender and Society17. 1, 33-53.

[24] Rody, Caroline. (2009). The Interethnic Imagination: Roots and Passages in Contemporary Asian American Fiction. New York: Oxford University Press.

[25] Taylor, A. (2000). 'The Sun Always in Perth': a Post-Colonial Geography of Identity, Memory and Place. Australian Geographical Studies 38.1, 27-35.

[26] Verkuyten, Maykel \& Peary Brug. (2004). Multiculturalism and Group Status: The Role of Ethnic Identification, Group Essentialism and Protestant Ethic. European Journal of Social Psychology 34.6, 647-661.

[27] Wong, Paul, Chienping Faith Lai, Richard Nagasawa \& Tieming Lin. (1998). Asian Americans as a Model Minority: Self-Perceptions and Perceptions by Other Racial Groups. Sociological Perspectives 41. 1, 95-118.

[28] Xie, Yu \& Kimberly Goyette. (1997). The Racial Identification of Biracial Children with One Asian Parent: Evidence from the 1990 Census. Social Forces76. 2, 547-570.

Lihua Zhao was born in Sichuan, China P.R. in 1972. She received Ph. D. of Arts from Sichuan University (Chengdu, China) in 2008. She is an English professor at China West Normal University (Nanchong, China). Her research focuses on American minority literature mainly. Her selected previous publications are: Skin Duality in Morrison's Paradise. Foreign Literature Review 104.4 (Beijing, China, 2012); Spatial Politics: A Study of Toni Morrison's Fictions (Chendu, China: Sichuan University Press, 2011); Baby Suggs' Decolonized Spatial Practice in Beloved, co-authored with Jian Shi. Contemporary Foreign Literature 113.3 (Nanjing, China, 2008). She is currently working on the spatial politics, spatial memory and spatial reconstruction of thirty American minority fictions. 